\title{
Effects of educational intervention on joint angles of the trunk and lower extremity and on muscle activities during patient-handling tasks
}

\author{
Toru Akebi · Masaiwa Inoue · Noriaki Harada
}

Received: 11 August 2008/Accepted: 4 December 2008/Published online: 15 January 2009

(C) The Japanese Society for Hygiene 2009

\begin{abstract}
Objective The objective of this study was to examine the effects of educational intervention on joint angles of the trunk and lower extremity and on muscle activities during patient-handling task.

Methods Thirty-two subjects (17 males and 15 females) volunteered for the study. They were classified into three groups: intervention group 1, comprised of first grade physical therapist students; control group, which included first grade occupational therapist students; intervention group 2, which comprised third grade physical therapist students. The educational intervention during the experimental period consisted of: (1) 12 regular classes and shortterm clinical practice for the students of intervention group 1; (2) long-term clinical practice, relating to patienthandling task, for the students of intervention group 2 . The following experiments were repeated before and after the educational intervention. Each subject was asked to transfer a male $(55 \mathrm{~kg})$ from one chair to a second chair (left to right) and then back again to the original chair (right to left). The flexion angles of the trunk, hip and knee joints were quantified by means of the dynamic threedimensional biomechanical analysis. Muscle activities (\% maximum voluntary contraction, \%MVC) of biceps brachii, trapezius, rectus femoris and erector spinae muscles were measured using surface electromyography (EMG). The effects of group, gender, measurement time and side on joint angles of trunk and lower extremity, \% MVC of four muscle activities and transfer time were assessed.
\end{abstract}

T. Akebi $\cdot$ M. Inoue $\cdot$ N. Harada $(\square)$

Department of Hygiene,

Yamaguchi University Graduate School of Medicine,

Minami-kogushi, Ube 755-8505, Japan

e-mail: harada@yamaguchi-u.ac.jp
Results Although the EMG analysis could not clearly demonstrate any reduction of physical load to the low back, the flexion angles of the hip and knee joints of student subjects during the patient-handling task became larger and that of the trunk became smaller in the group given the educational intervention.

Conclusion The finding of this study suggests that the posture of the study subjects changed to the squat lifting method, which is preferable for reducing the physical load to the lower back, as a result of the educational intervention.

Keywords Biomechanical analysis - Educational intervention - Low back pain - Patient-handling task . Surface electromyography

\section{Introduction}

Eighty percent of all human beings experience lumbago at some time in their life, a condition fated for the human species since it began to walk with two-legged posture [1]. Various work-related musculoskeletal disorders, including lumbago, are common among individuals working in the medical and nursing care field [2-8]; however, little has been reported about the incidence of such disorders among physiotherapists in Japan [9]. Several researchers have pointed out the significance of patient-handling tasks, such as transferring patients, as the cause of lumbago [2, 10-15], and a large number of reports on the effect of educational intervention on the prevention of lumbago resulting from patient-handling tasks among nurses and nursing students have been published. Yassi et al. [7] reported that physical load to low back during patient-handling task was reduced by technical and concentrated training as well as by 
introducing the appropriate supporting equipment for the task [16]. The effectiveness of educational intervention for lumbago prevention among nurses working in hospitals has also been reported [17-19]. Johnsson et al. [20] observed positive effects of educational intervention on work technique scores and ratings of comfort, safety and exertion among nursing students. Smedley et al. [16] reported that the use of supportive equipment when carrying out patienthandling tasks reduced the risk of low back pain relative to those carried out by manual handling. In contrast, there are some negative reports regarding the effect of educational intervention. In one study, a concentrated educational intervention did not appear to have any significant effect compared with a one-time guidance without practice [21]. Allen et al. [8] also reported that an educational intervention using sufficient techniques did not show any significant difference in physical load with or without supporting equipment. There is no agreement among researchers on the effects of educational intervention and supporting equipment for reducing the physical load of practitioners.

In terms of work-related musculoskeletal disorders among physical therapists in Japan, it has been reported that the body part prone to the highest risk of injury is the low back and that about $70 \%$ of physical therapists have such experiences [9], with biomechanical physical load to the low back during patient-transfer generally pointed out as the cause [9]. Most physical therapists transfer patients manually, either alone or with the help of co-workers; they usually do not use supporting equipment. Therefore, it would seem to be important to reduce the physical load to the low back during patient-handling task. There have been a number of recent studies on the physical load during patient-handling task using a three-dimensional (3D) biomechanical analysis [22-25]. However, to date, the effect of educational intervention on the physical load to the low back during patient-transfer task has not been assessed by such a 3D system for the analysis. The aim of this study was to examine the effects of educational intervention on the joint angles of the trunk and lower extremity and on muscle activities during a patient-handling task by using
3D biomechanical analyzer and surface electromyography (EMG).

\section{Subjects and methods}

Subjects

Thirty-two subjects, who were special school students in the department of physical and occupational therapy, volunteered for the study. None of the subjects had musculoskeletal disorders at the time of the study and had a regular daily exercise regime. They were classified into three groups: (1) intervention group 1, comprised of first grade physical therapist students (six males and seven females); (2) control group, incuding first grade occupational therapist students (six males and four females); (3) intervention group 2, comprising third grade physical therapist students (five males and four females). The physical/demographic characteristics of the intervention and control groups at baseline are shown in Table 1. The schedule of educational intervention in the school is shown in Fig. 1.

\section{Educational intervention}

\section{Intervention performed during regular classes for the first grade students}

The educational intervention was carried out as a part of the regular class curriculum. One of the major aims of these classes is to teach physical therapists the proper method for reducing physical load when carrying out patient-handling tasks, from a biomechanical point of view. The main focus of such classes is providing an understanding of the most effective assistance methods for reducing body loads while transferring a patient. During the educational intervention, attention was given to such aspects as changing the posture of student subject according to the so-called "first-class lever". This is the lever of balance, with a subject's knee joint functioning as the

Table 1 Physical/demographic characteristics of experiment and control groups at baseline

\begin{tabular}{|c|c|c|c|c|c|c|}
\hline \multirow{3}{*}{$\begin{array}{l}\text { Physical/demographic } \\
\text { characteristics of study group }\end{array}$} & \multicolumn{4}{|c|}{ First grade student } & \multirow{2}{*}{\multicolumn{2}{|c|}{$\frac{\text { Third grade student }}{\text { Intervention group } 2}$}} \\
\hline & \multicolumn{2}{|c|}{ Intervention group 1} & \multicolumn{2}{|c|}{ Control group } & & \\
\hline & Male & Female & Male & Female & Male & Female \\
\hline$n$ & 6 & 7 & 6 & 4 & 5 & 4 \\
\hline Age (year) & $21.2 \pm 4.5$ & $18.4 \pm 0.5$ & $19.3 \pm 2.8$ & $18.3 \pm 0.5$ & $23.6 \pm 3.0$ & $23.0 \pm 4.7$ \\
\hline Height $(\mathrm{cm})$ & $170.8 \pm 2.6$ & $157.7 \pm 7.5$ & $168.8 \pm 6.3$ & $154.0 \pm 4.2$ & $169.2 \pm 4.6$ & $160.3 \pm 8.8$ \\
\hline Weight (kg) & $62.0 \pm 6.1$ & $51.4 \pm 5.6$ & $58.0 \pm 1.9$ & $48.0 \pm 3.7$ & $61.4 \pm 3.0$ & $53.5 \pm 4.9$ \\
\hline
\end{tabular}

Values are shown as mean $\pm \mathrm{SD}$ 
Fig. 1 Schedule of experiments. The term intervention denotes an educational intervention relating to a patient-handling task carried out by students

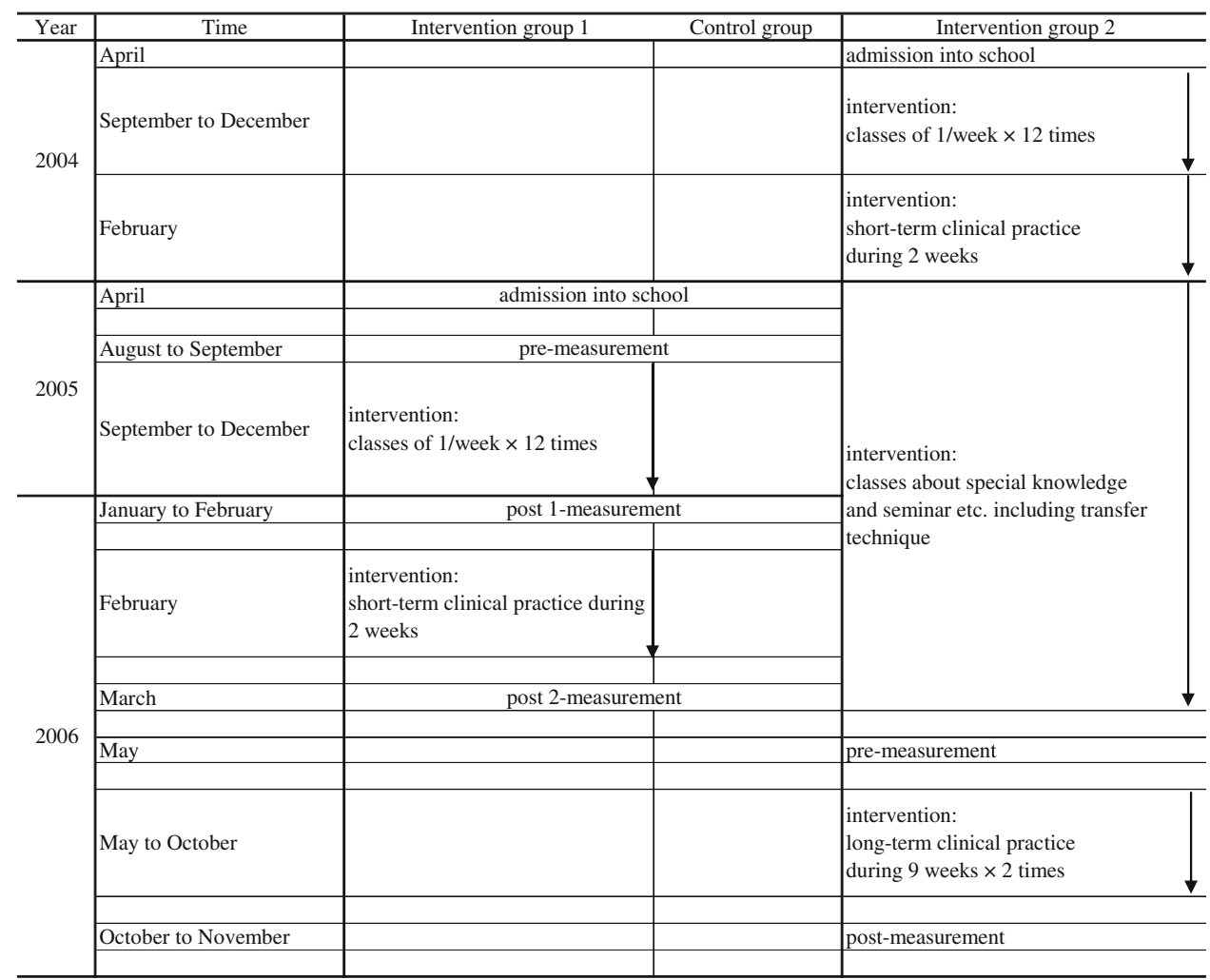

fulcrum, their center of gravity as the emphasis and the center of gravity of the transferred person as the action point. Emphasis was given on bending the upper-body of the transferred person forward after the student's knee joints were bent, thereby lowering the position of the center of gravity, and then lifting the transferred person and raising his position from the center of gravity as soon as his buttocks was off from the chair. Following standard teaching procedure, 12 regular classes were provided for physical therapist students. The first half of the intervention course mainly consisted of lectures, including those on biomechanics; the latter half was practical work, including patient-handling tasks, such as wheelchair operation, rolling, sitting on, standing up and transfer activities. There were two classes on tasks related to transferring the patient from a chair to another chair. The teacher in charge of these classes was unaware of this study.

\section{Intervention performed during short-term clinical practice for the first grade students}

Short-term clinical practice was provided in the form of observation of how the supervisor performed physiotherapy, for 2 weeks in February. This practical work was done to provide the students with an understanding of the physical therapist's work and the role of such work in clinical practice.
Intervention performed at long-term clinical practice for the third grade students

Long-term clinical practice was implemented twice for 9 weeks from May to October for the third grade students. This practice was performed during the final stage of the educational program, to summarize the school education. The method of patient-handling experienced at the practice was similar to the method of this experiment; however, the experience level was different, depending on the severity of symptoms of patients and practice facilities used.

\section{Experimental procedure}

\section{Measurement time}

The intervention schedule en type of intervention is shown in Fig. 1. Intervention group 1 (the first grade students at baseline) was assessed three times as follows: before classes pertaining to the intervention (pre-measurement), after the classes (post 1-measurement) and after the shortterm clinical practice (post 2-measurement). The control group (the first grade students at baseline) was also assessed at the same time. Intervention group 2 (the third grade students) was assessed twice as follows: before the long-term clinical practice (pre-measurement) and thereafter (post-measurement). 


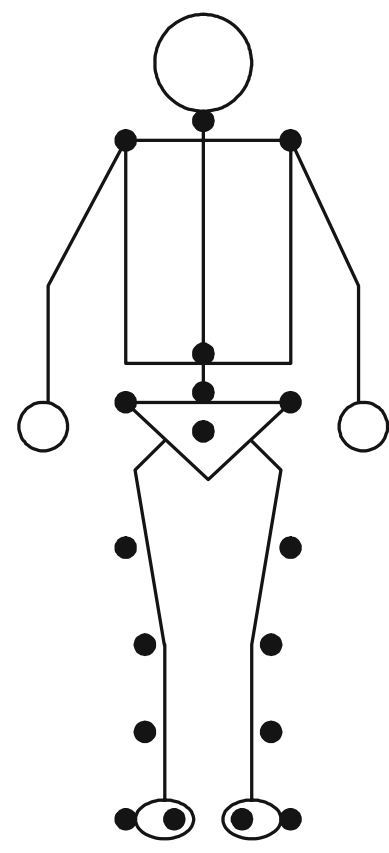

(a)

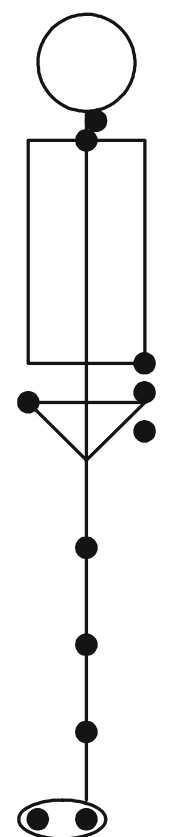

(b)
Fig. 2 Position of infrared markers for measurement using a dynamic three-dimensional biomechanical analyzer. a Frontal plane, b Sagittal plane

\section{Patient-transferring task}

Prior to the experiments, height, weight, right and left grip forces and back muscle strength of all subjects were measured and their exercise habits checked. The subjects performed stretching exercises as a preparation for the measurement and then they performed a trial involving a patient-transferring task. The subjects were then asked to transfer a 55-kg male from one chair to another-from left right - and then to return him to the original chair (right to left transfer) [26]. The chair was a round type, $40 \mathrm{~cm}$ in height, $30 \mathrm{~cm}$ in diameter; the distance between the center of the left chair and the center of the right chair was about $70 \mathrm{~cm}$.

\section{Biomechanical measurement}

Flexion angles of the trunk, hip and knee joints were quantified by means of the dynamic 3D biomechanical analysis Peak Motus 4.3 system (Peak Performance Technologies, Englewood, $\mathrm{CO}$ ); infrared markers were fixed on 20 body parts, as shown in Fig. 2. For this purpose, six infrared cameras were used and the results digitized automatically with the Peak Motus 4.3 system. The angles were evaluated according to the criteria of Japanese Orthopedic Association and Japanese Association of Rehabilitation Medicine as shown in Fig. 3.

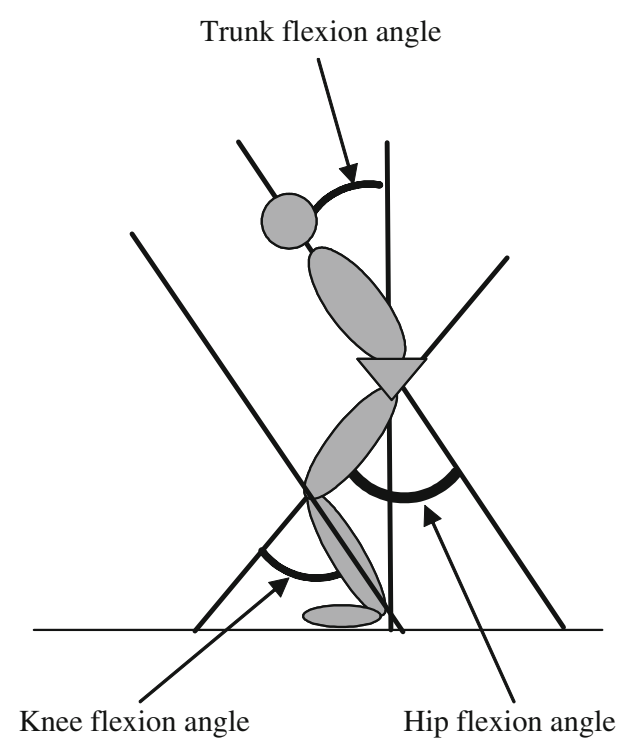

Fig. 3 Flexion angle in each joint

\section{Electromyography measurement}

EMG was used to examine the muscle activities of four muscle groups (biceps brachii, trapezius, rectus femoris and erector spinae) during both directions of the patienttransferring task. Pre-gelled $\mathrm{Ag} / \mathrm{AgCl}$ bipolar surface electrodes were used. After shaving the skin of the student at the point of attachment and cleaning it with alcohol, the electrodes were placed on the skin at the midpoint of the biceps brachii, about $2 \mathrm{~cm}$ lateral to the midpoint of the line between the spinous process of the seventh cervical vertebra and the acromion, the midpoint of the line between the anterior superior iliac spine and the patella, and approximately $4 \mathrm{~cm}$ outside and $3 \mathrm{~cm}$ above of the spinous process of the fifth lumbar vertebra. Before beginning the experiments, maximum voluntary contraction (MVC) of each muscle was measured based on manual muscle testing [27]. Muscle activities during the patienttransferring task were normalized using MVC of each muscle as \%MVC.

To record the EMG, we used the Noraxon Myosystem 1200 (Noraxon, Scottsdale, AZ); Noraxon MyoResearch Software (Noraxon) was used for the analysis.

Statistical analysis

The values of the joint angles, \%MVC of the muscles and transfer time in both directions were measured. The interval between the time points when the buttocks of the subject left the chair and when they touched the next chair was calculated. Average values of both directions for each measurement were used for analyses. Statistical analyses were performed using multivariate analysis of variance 
(MANOVA). We examined the effects of group (intervention group or control group), gender (male or female), measurement time (pre-measurement, post 1-measurement or post 2-measurement) and side (right or left) on joint angles of trunk, hip and knee, the \%MVC of four muscles and the transfer time in the first grade students. In the third grade students, similar analyses were performed except for the effect of group. Results were considered to be significant at the alpha level of 0.05 .

\section{Research ethics}

All subjects provided written informed consent, and this study was approved by the Institutional Review Board of Yamaguchi University Hospital (No. H17-44).

\section{Results}

Changes in biomechanical variables as a result of the educational intervention in the first grade students

Table 2 shows the values of the joint angles, muscle activities and transfer time before and after the intervention in the first grade students and the results of the MANOVA.

\section{Joint angle}

The effects of group on the flexion angles of hip and knee joints were statistically significant $(p<0.001$, respectively); the angles of intervention group 1 were larger than those of the control group. The effects of gender on the flexion angles of hip and knee joints were also statistically significant $(p=0.012,<0.001)$, with those of the male students being larger than those of the female ones. The effects of measurement time on the flexion angles of the hip and knee joints were statistically significant ( $p=0.020,0.008$, respectively), with the flexion angles at the post 1-measurement and post 2-measurement being larger than those at the pre-measurement. However, a significant interaction between group and measurement time was observed for the flexion angle of the knee joint $(p=0.047$; result not shown).

The trunk flexion angle of intervention group 1 tended to be smaller than that of the control group $(p=0.155)$, with a tendency for the flexion angles at the post 1-measurement and post 2-measurement to be smaller than that at the premeasurement $(p=0.116)$, although no significant effect of group, gender or measurement time on the flexion angle of trunk was observed.

\section{Muscle activities}

The effect of group on the \%MVC of biceps brachii muscles was statistically significant $(p=0.034)$, with the muscle activity of the intervention group being smaller than that of the control group. The effects of gender and measurement time on the \%MVC of biceps brachii muscles were not statistically significant. However, a significant interaction between measurement time and gender was observed for the \%MVC of biceps brachii muscles ( $p=0.034$; result not shown).

The effect of gender on the \%MVC of trapezius muscles was statistically significant $(p<0.001)$, with the muscle activity of the female student being larger than that of the male student. The effect of side on the \%MVC of trapezius muscles was statistically significant $(p=0.015)$, and the muscle activity of right was larger than that of left.

The effect of group on the \%MVC of rectus femoris muscles was not statistically significant $(p=0.085)$, although the muscle activity of the control group was larger than that of the intervention group. The effect of gender on the \% MVC of rectus femoris muscles was statistically significant $(p<0.001)$, with muscle activity of the female student being larger than that of the male student. The effect of measurement time on the \%MVC of rectus femoris muscles was not statistically significant $(p=$ 0.052 ), although muscle activity at the post 1-measurement and post 2-measurement was larger than that at the pre-measurement. However, a significant interaction between measurement time and gender was observed for the \%MVC of rectus femoris muscles $(p=0.012$; result not shown).

The effect of group on the \%MVC of erector spinae muscles was statistically significant $(p=0.003)$, with the muscle activity of the control group being larger than that of the intervention group. The effect of gender on the $\% \mathrm{MVC}$ of erector spinae muscles was statistically significant $(p<0.001)$; the muscle activity of the female was larger than that of the male. However, a significant interaction between group and gender was observed for the $\%$ MVC of erector spinae muscles $(p=0.002$; result not shown). The effect of measurement time on the \%MVC of erector spinae muscles was not statistically significant $(p=0.131)$, although the muscle activity at the post 1 measurement and post 2-measurement was larger than that at the pre-measurement.

\section{Transfer time}

The effect of group on the transfer time was statistically significant $(p<0.001)$, with the transfer time of the control group being longer than that of the intervention group. The effect of gender on the transfer time was statistically 


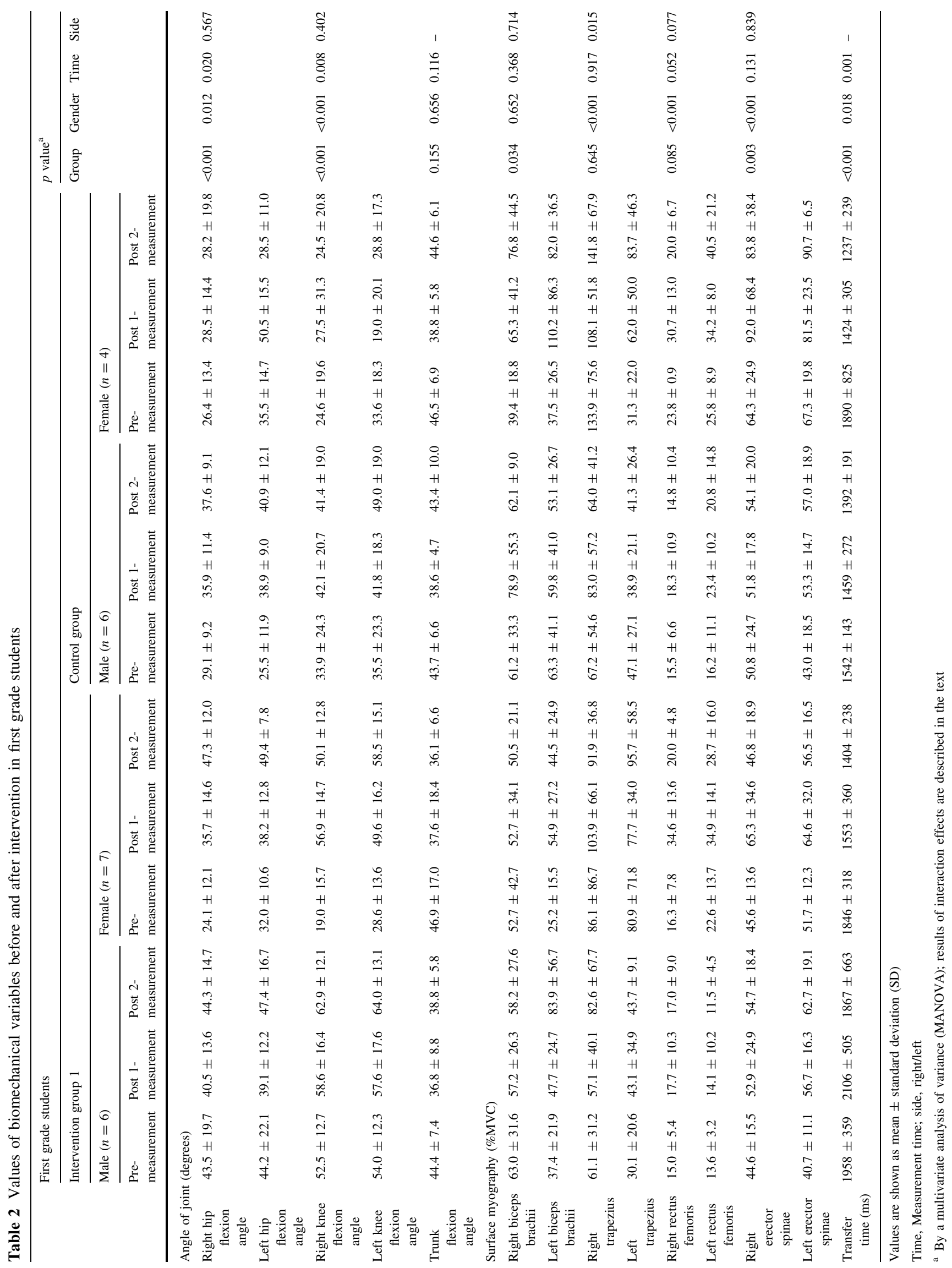


significant ( $p=0.018$ ) the transfer time of the male student was longer than that of the female student. The effect of measurement time on the transfer time was statistically significant ( $p=0.001)$, with the transfer time at the post 1measurement and post 2-measurement being shorter than that at the pre-measurement. However, a significant interaction between group and gender was observed for transfer time ( $p=0.002$; result not shown).

Changes in biomechanical variables by educational intervention in the third grade students

Table 3 shows the values of joint angles, muscle activities and transfer time before and after intervention in the third grade students, and the results of the MANOVA.

\section{Joint angle}

The effects of gender on the flexion angles of the hip and knee joints were not statistically significant $(p=0.092$, 0.317), although the flexion angles of hip and knee joints of the male were larger than those of the female. No significant effect of measurement time or side was found for the flexion angles of hip and knee joints. The effect of measurement time on the flexion angle of trunk was statistically significant ( $p=0.001)$; the angle at the post-measurement was smaller than that at the pre-measurement.

\section{Muscle activities}

The effect of gender on the \%MVC of biceps brachii muscles was not statistically significant $(p=0.059)$, although the muscle activity of the male students was larger than that of the female students. The effects of measurement time and gender on the \%MVC of trapezius muscles were not statistically significant $(p=0.156$, 0.059 ), although the muscle activities at the post-measurement and for the female students were larger than those at the pre-measurement and for the male students. The effect of gender on the \%MVC of rectus femoris muscles was not statistically significant $(p=0.095)$, although the muscle activity of the female students was larger than that of the male students. No significant effects of measurement time, gender or side on the \% MVC of erector spinae muscles were observed.

\section{Transfer time}

The effect of gender on the transfer time was statistically significant ( $p=0.006)$, with the transfer time of the female

Table 3 Values of biomechanical variables before and after intervention in third grade students

\begin{tabular}{|c|c|c|c|c|c|c|c|}
\hline \multirow[t]{3}{*}{ Biomechanical variables } & \multirow{2}{*}{\multicolumn{4}{|c|}{$\frac{\text { Third grade students }}{\text { Intervention group } 2}$}} & \multicolumn{3}{|l|}{$p$ value $^{\mathrm{a}}$} \\
\hline & & & & & \multirow[t]{2}{*}{ Gender } & \multirow[t]{2}{*}{ Time } & \multirow[t]{2}{*}{ Side } \\
\hline & $\begin{array}{l}\text { Male }(n=5) \\
\text { Pre-measurement }\end{array}$ & Post-measurement & $\begin{array}{l}\text { Female }(n=4) \\
\text { Pre-measurement }\end{array}$ & Post-measurement & & & \\
\hline \multicolumn{8}{|l|}{ Angle of joint (degrees) } \\
\hline Right hip flexion angle & $40.9 \pm 7.4$ & $47.9 \pm 9.0$ & $33.7 \pm 6.4$ & $33.5 \pm 10.4$ & 0.092 & 0.838 & 0.821 \\
\hline Left hip flexion angle & $40.3 \pm 9.7$ & $39.5 \pm 24.8$ & $37.6 \pm 5.8$ & $34.9 \pm 12.9$ & & & \\
\hline Right knee flexion angle & $70.0 \pm 11.2$ & $77.4 \pm 3.4$ & $68.4 \pm 8.3$ & $70.5 \pm 4.6$ & 0.317 & 0.301 & 0.552 \\
\hline Left knee flexion angle & $72.7 \pm 13.0$ & $74.6 \pm 3.1$ & $72.8 \pm 8.3$ & $72.4 \pm 3.3$ & & & \\
\hline Trunk flexion angle & $44.8 \pm 22.8$ & $31.5 \pm 8.3$ & $46.7 \pm 16.9$ & $22.1 \pm 6.3$ & 0.466 & 0.001 & - \\
\hline \multicolumn{8}{|c|}{ Surface myography (\%MVC) } \\
\hline Right biceps brachii & $67.2 \pm 40.1$ & $108.9 \pm 116.6$ & $14.4 \pm 6.6$ & $37.1 \pm 27.9$ & 0.059 & 0.241 & 0.630 \\
\hline Left biceps brachii & $81.5 \pm 56.2$ & $81.6 \pm 74.8$ & $32.1 \pm 22.0$ & $76.8 \pm 102.8$ & & & \\
\hline Right trapezius & $48.0 \pm 5.4$ & $86.8 \pm 59.0$ & $65.5 \pm 35.1$ & $121.5 \pm 31.2$ & 0.088 & 0.156 & 0.702 \\
\hline Left trapezius & $69.1 \pm 20.8$ & $73.9 \pm 19.1$ & $105.0 \pm 111.7$ & $98.4 \pm 35.7$ & & & \\
\hline Right rectus femoris & $24.9 \pm 12.4$ & $39.1 \pm 25.0$ & $44.2 \pm 14.5$ & $33.3 \pm 7.4$ & 0.095 & 0.699 & 0.473 \\
\hline Left rectus femoris & $24.1 \pm 15.3$ & $27.3 \pm 18.0$ & $36.3 \pm 15.8$ & $38.3 \pm 5.7$ & & & \\
\hline Right erector spinae & $56.0 \pm 13.7$ & $52.8 \pm 14.8$ & $56.3 \pm 35.9$ & $48.5 \pm 26.7$ & 0.783 & 0.828 & 0.983 \\
\hline Left erector spinae & $52.2 \pm 7.8$ & $49.0 \pm 14.8$ & $52.5 \pm 23.3$ & $60.5 \pm 28.0$ & & & \\
\hline Transfer time (msec) & $1529 \pm 354$ & $1479 \pm 147$ & $1717 \pm 459$ & $1968 \pm 403$ & 0.006 & 0.390 & - \\
\hline
\end{tabular}

Values are shown as mean $\pm \mathrm{SD}$

Time, Measurement time; side right/left

a By MANOVA; results of interaction effects are described in the text 
being longer than that of the male. The effect of measurement time on the transfer time was not statistically significant $(p=0.390)$; however, significant interaction between measurement time and gender was observed $(p=0.016$; result not shown).

\section{Discussion}

The results of this study suggest that an educational intervention may lead to improvements in patient-handling tasks with respect to reducing physical load. Relative to the control group, in the first grade students, the flexion angles of the hip and knee joints were larger and the flexion angle of the trunk was smaller in the intervention group. Furthermore, the flexion angles of the hip and knee joints were larger and the flexion angle of the trunk was smaller at the post-measurement than at the pre-measurement, indicating that the intervention group tended to change their posture to a squat lifting style, which is the posture with large flexion angles of hip and knee joints and extended trunk. In the third grade students, the flexion angles of the hip and knee joints did not change significantly due to the educational intervention; one reason for this result may be that their angles were already large enough at the pre-measurement. However, the smaller flexion angle of the trunk at the post-measurement indicates that the third grade students also tended to change their posture to a squat lifting style.

As observed in our study, educational intervention led the student subjects to change to the squat lifting style by applying the "first-class lever". Fujimura et al. [28] reported that the muscle activity of the rectus femoris was larger and that of erector spinae was smaller in therapists applying the squat lifting style than in those applying the stoop lifting style; therefore, the physical load of the low back with the squat lifting style was lower than that with the stoop lifting style. As revealed in our study, educational intervention seemed to be effective in changing the posture of our student subjects during patient-handling task.

Muscle activities of the biceps brachii of the intervention group were significantly smaller than those of the control group among the first grade students. This finding suggests that the physical load to the upper extremities was reduced as a consequence of the educational intervention. However, although gender and side were significant factors for the muscle activities of trapezius in the first grade students, they were not statistically significant in the third grade students. The reason for this may be the muscular power difference between the male and the female, which affected the muscle activities of the first grade students. However, the muscle activities of the biceps brachii were not significantly different between the male and the female students. This inconsistency is probably due to the differences in flexion angles of the elbow joints during the patient-handling task between the male and the female students. We speculate that the male students mainly mobilized the muscle biceps brachii while the female students tried to accomplish patient-handling task using the entire upper limbs. As the muscle activities of the biceps brachii were significantly different between the right and left sides, this seemed to result from grasping power differences between the sides (male: $42.3 \mathrm{~kg}$ for right and $40.3 \mathrm{~kg}$ for left; female: $25.0 \mathrm{~kg}$ for right and $24.8 \mathrm{~kg}$ for left). The right hand was dominant in most of the subjects. In the third grade students, we guessed that the muscle activities of the upper limbs as well as the joint angles of the lower limbs were reduced even before the intervention as long-term clinical practice. The muscle activities of the rectus femoris did not indicate statistically significant differences among groups, measurement times and sides, but they did indicate significant differences between male and female subjects in the first grade students. We considered the muscle activities of rectus femoris of the male student to have decreased because the muscle strength of the male student was stronger than that of the female student. The muscle activities of the erector spinae of the intervention group were significantly smaller than those of the control group. This finding suggests that there was a suppression of muscle activity by the educational intervention. Keir et al. [29] and Hirabayashi et al. [30] reported that the experienced person performed patient-handling task with smaller muscle activity of erector spinae than did the novice as a result of the former's higher skill level. Our findings of smaller muscle activities of erector spinae correspond well with these conclusions. However, no significant differences among measurement times were observed. There are a number of likely reasons for this-frequency of using these muscles, the short intervention period and the different experiences among students during the clinical practice period. Gender was shown to be a significant factor for the muscle activities of erector spinae. We assumed that, due to difference in the strength of muscular power, the female had mobilized the muscle activities of erector spinae more than those of the male. However, in the third grade students, the gender difference in muscle activities of the erector spinae was lost in the intervention group, probably as an effect of educational intervention.

The transfer time of the intervention group became significantly longer than that of the control group, and there was a significant interaction between group and gender for transfer time in the first grade students. We assumed that the male students in the intervention group were relatively more careful in performing the patient-handling task and, therefore, their transfer time was slower. In contrast, in the third grade students, there was significant difference in 
transfer time among the genders, and a significant interaction between measurement time and gender were observed. However, the results did not indicate any difference between pre-measurement and post-measurement. These findings reflect that finding that the transfer time of male students at the post-measurement was shorter than that at the pre-measurement; the findings for the female students were the opposite. As the male students had stronger muscular power compared with the female students, the former could effectively perform the task with shorter time after the intervention as a long-term clinical practice course. Thus, the male students could reduce the physical load of manual handling task. On the other hand, to reduce the physical load, the female students with weaker muscular power performed the task carefully with a longer transfer time. Our findings are in agreement with the results of Lindbeck et al. [31], who also found gender differences in terms of the manual lifting technique for heavy material. These researchers concluded that males and females must be considered separately when evaluating the work technique in manual handling tasks.

There are numerous reports [7, 16-21] on the effect of educational interventions for preventing lumbago among health care practitioners carrying out patient-handling tasks. However, little information is available on the effect of educational intervention for physical therapists. Moreover, there is also a lack of longitudinal reports based on a biomechanical evaluation. In most prior studies, a questionnaire was used to evaluate musculoskeletal disorders. Also, most of the intervention methods consisted of the introduction of mechanical assistive devices or educational instruction or both; composite methods were mostly used for intervention. However, very few studies have examined the effectiveness of longterm educational intervention by lectures or clinical practical work alone using a longitudinal approach. Therefore, we consider that our results, which show positive effects of an educational intervention on physical load reduction during patient-handling task, as evaluated by the measurement of trunk and lower extremity joint angles and muscle activities, are valuable.

One of the limitations of this study was the small sample size, for which we were not able to adequately explain the gender difference. Secondly, there may be questions regarding the quantitative and qualitative issue of the intervention for the student subjects. The frequency of classes for the students was not adequate and the extent of experience during clinical practice was different among students according to hospitals and facilities visited by them. Another limitation of this study was that no control group was used for intervention group 2 as no suitable control subjects were available. Future studies with a larger sample size are necessary to investigate the effects of gender, intervention period and quality of intervention on physical load reduction during patient-handling tasks.

\section{Conclusion}

Our study has demonstrated that flexion angles of the hip and knee joints of student subjects during a patient-handling task became larger and that of the trunk became smaller as a consequence of an educational intervention. This result means that the posture of student subjects changed to the squat lifting method, which is preferable for reducing the physical load to the low back. However, the EMG analysis could not clearly demonstrate any reduction in the physical load to the low back, although the muscle activity of erector spinae tended to decrease and the muscle activity of rectus femoris tended to increase. Further study, including a larger number of subjects together with analyses of the effects of gender, intervention period and quality of intervention, is required to confirm the effects of educational intervention on physical load reduction during patient-handling task.

Acknowledgments We wish to thank all the students of Aso Rehabilitation College who participated in this study and also thanks to Dr. Hossain Md. Mahbub of Department of Hygiene, Yamaguchi University Graduate School of Medicine, for thoroughly checking the manuscript.

\section{References}

1. Shirado O, Kaneda K. Treatment of occupational low-back pain. Introduction of backschool and considerations on surgical management (in Japanese). J Musculoskelet Syst. 1993;6:673-82.

2. Burdorf A, Sorock G. Positive and negative evidence of risk factors for back disorders. Scand J Work Environ Health. 1997;23:243-56.

3. French P, Flora LF, Ping LS, Bo LK, Rita WH. The prevalence and cause of occupational back pain in Hong Kong registered nurses. J Adv Nurs. 1997;26:380-8.

4. Pheasant S, Stubbs D. Back pain in nurses: epidemiology and risk assessment. Appl Ergon. 1992;3:226-32.

5. Buckle P. Epidemiological aspects of back pain within the nursing profession. Int J Nurs Stud. 1987;4:319-24.

6. Owen BD, Damron CF. Personal characteristics and back injury among hospital nursing personnel. Res Nurs Health. 1984; 7:305-13.

7. Yassi A, Cooper JE, Tate RB, Gerlach S, Gerlach S, Muir M, et al. A randomized controlled trial to prevent patient lift and transfer injuries of health care workers. Spine. 2001;26:1739-46.

8. Allen R, Jackson S, Marsden H, McLellan DL, Gore S. Transferring people safely with manual handling equipment. Clin Rehabil. 2002;16:329-37.

9. Saito H, Miyamoto K, Kasahara S, Morita Y, Takahashi M, Kawamura N, et al. Occupational musculoskeletal injury in physical therapists in Japan (in Japanese). J Jpn Phys Ther Assoc. 2002;29:134-40.

10. Harber P, Billet E, Gutowski M, SooHoo K, Lew M, Roman A. Occupational low-back pain in hospital nurses. J Occup Med. 1985;27:518-24. 
11. Hoogendoorn WE, van Poppel MN, Bongers PM, Koes BW, Bouter LM. Physical load during work and leisure time as risk factors for back pain. Scand J Work Environ Health. 1999; 25:387-403.

12. Stubbs DA, Buckle PW, Hudson MP, Rivers PM, Worringham CJ. Back pain in the nursing profession. I. Epidemiology and pilot methodology. Ergonomics. 1983;26:755-65.

13. Stubbs DA, Buckle PW, Hudson MP, Rivers PM. Back pain in the nursing profession. II. The effectiveness of training. Ergonomics. 1983;26:767-79.

14. Vasiliadou A, Karvountzis GG, Soumilas A, Roumeliotis D, Theodosopoulou E. Occupational low-back pain in nursing staff in a Greek hospital. J Adv Nurs. 1995;21:125-30.

15. Smith DR, Kondo N, Tanaka E, Tanaka H, Hirasawa K, Yamagata Z. Musculoskeletal disorders among hospital nurses in rural Japan. Rural Remote Health. 2003;3:241.

16. Smedley J, Egger P, Cooper C, Coggon D. Manual handling activities and risk of low back pain in nurses. Occup Environ Med. 1995;52:160-3.

17. Fanello S, Frampas-Chotard V, Roquelaure Y, Jousset N, Delbos $\mathrm{V}$, Jarny J, et al. Evaluation of an educational low back pain prevention program for hospital employees. Rev Rhum Engl Ed. 1999;66:711-6.

18. Fanello S, Jousset N, Roquelaure Y, Chotard-Frampas V, Delbos $\mathrm{V}$. Evaluation of a training program for the prevention of lower back pain among hospital employees. Nurs Health Sci. 2002;4:51-4.

19. Menzel NN, Lilley S, Robinson ME. Interventions to reduce back pain in rehabilitation hospital nursing staff. Rehabil Nurs. 2006;31:138-47.

20. Johnsson AC, Kjellberg A, Lagerström MI. Evaluation of nursing students' work technique after proficiency training in patient transfer methods during undergraduate education. Nurse Educ Today. 2006;26:322-31.

21. Hartvigsen J, Lauritzen S, Lings S, Lauritzen T. Intensive education combined with low tech ergonomic intervention does not prevent low back pain in nurses. Occup Environ Med. 2005;62:13-7.

22. Scotte JH. Estimation of low back loading on nurses during patient handling tasks: the importance of bedside reaction force measurement. J Biomech. 2001;34:273-6.

23. Daynard D, Yassi A, Cooper JE, Tate R, Norman R, Wells R. Biomechanical analysis of peak and cumulative spinal loads during simulated patient-handling activities: a substudy of a randomized controlled trial to prevent lift and transfer injury of health care workers. Appl Ergon. 2001;32:199-214.

24. Skotte JH, Essendrop M, Hansen AF, Schibye B. A dynamic 3D biomechanical evaluation of the load on the low back during different patient-handling tasks. J Biomech. 2002;35:1357-66.

25. Schibye B, Hansen AF, Hye-Knudsen CT, Essendrop M, Bocher M, Skotte J. Biomechanical analysis of the effect of changing patient-handling technique. Appl Ergon. 2003;34:115-23.

26. Marras WS, Davis KG, Kirking BC, Bertsche PK. A comprehensive analysis of low-back disorder risk and spinal loading during the transferring and repositioning of patients using different techniques. Ergonomics. 1999;42:904-26.

27. Helen JH, Jacqueline M. Daniels and Worthingham's muscle testing: techniques of manual examination, 8th edn. Philadelphia: WB Saunders; 2007.

28. Fujimura M, Nara I. The influence on lumbago in lifting weights measured by electromyography (in Japanese). Jpn J Occup Med Traumatol. 2004;52:341-7.

29. Keir PJ, MacDonell CW. Muscle activity during patient transfers: a preliminary study on the influence of lift assists and experience. Ergonomics. 2004;47:296-306.

30. Hirabayashi G, Sugihara M, Go T, Ogawa K, Kasahara H. Relationship between the amount of assistance and the muscular activity level in motion with assistance (in Japanese). J Jpn Phys Ther Assoc. 1999;26:187-91.

31. Lindbeck L, Kjellberg K. Gender differences in lifting technique. Ergonomics. 2001;44:202-14. 